\title{
Preface
}

\section{Colonized by Data}

The telegraph pole, the Christian cross, and the rifle arrived all at once for the Bororo people of Mato Grosso. The rifle of the soldier and the settler served to seize the Bororo's land in the name of industry and progress, the cross "pacified" and "civilized" them, and the telegraph integrated them into the rest of the newly wired Brazilian republic in the mid-nineteenth century. ${ }^{1}$ Some Bororo donned western clothing and moved from communal to single-family dwellings, as the priests told them to do. They learned the settlers' language and were put to work on the construction of the national telegraph network.

Such history is what comes to mind when most of us think of colonialism. Yet we know that the effects of colonialism continue to be felt, as indigenous people even today resist dispossession, cultural invasion, and genocide. Consider next another starting point, the Idle No More movement, a campaign by indigenous peoples in Canada to protect their ancestral resources. ${ }^{2}$ Like many activist movements, Idle No More has become a smart user of social media to promote its cause and enlist supporters. The telegraph pole used to link the Bororo into networks of colonial power has given way to a tool on which even the victims of colonization would now seem to depend. Nonetheless, the implications of such tools are, at best, ambiguous. Reflecting on the use of social media during the campaign's protests, Leanne Betasamosake Simpson, a scholar, writer, and artist of the Nishnaabeg people, wrote that "every tweet, Facebook post, blog post, Instagram photo, YouTube video, and email we sent during Idle No More made the largest corporations in the world ... more money to reinforce the system of settler colonialism. . . I I wonder in hindsight if maybe we didn't 
build a movement, but rather we built a social media presence that privileged individuals over community, virtual validation over empathy, leadership without accountability and responsibility."3

Consider now a third starting point-the question that Irish novelist Sally Rooney, dubbed "the J. D. Salinger of the Snapchat generation," recently asked herself: "Why wasn't I drinking enough water?"4 Following a series of fainting spells, doctors advised her to increase her hydration because, like many busy people, she sometimes forgets to take a water break. Fortunately, as the cliché goes, there's an app for that. The makers of WaterMinder offer a program to bypass the part of the brain that regulates thirst, reminding you to drink regularly to meet predefined quotas while tracking your progress. Like many apps, the program claims to turn what would otherwise be an insignificant private act into a social celebration, allowing you to earn achievements that you can share with your friends. "Makes water fun again," wrote a reviewer of the app.

The continuity between the first and second starting points is clear, but what of the third? It might seem counterintuitive to imagine that colonialism's sites of exploitation today include the very same West that historically imposed colonialism on the rest of the world. But what if the armory of colonialism is expanding? What if new ways of appropriating human life, and the freedoms on which it depends, are emerging? That is the disturbing possibility that we explore in this book.

Let's look at Sally Rooney's story again. The simple, daily act that every individual body does of monitoring whether it has drunk enough water has suddenly become something that happens in a competitive social space. The human body has been reworked into something that requires a distant infrastructure, from which, incidentally, profit can be made. In Rooney's own words, "I have contracted out one of the essential functions of my body to a piece of software." But this is just one small example of something much bigger: the systematic attempt to turn all human lives and relations into inputs for the generation of profit. Human experience, potentially every layer and aspect of it, is becoming the target of profitable extraction. We call this condition colonization by data, and it is a key dimension of how capitalism itself is evolving today. 
If colonialism is the problem, you may be thinking, Isn't the solution as simple as calling for the internet to be decolonized, liberating us all? After all, there have been calls to decolonize everything from schools to museums and ways of thinking. But uttered too easily, such calls risk making anyone and everyone into metaphorical subalterns, serfs, or slaves of Silicon Valley. Such metaphorical complaints leave intact the social and economic order that colonialism comprises at its core. It is not enough to "play Indian." As Eve Tuck and K. Wayne Yang remind us, colonization "is not an approximation of other experiences of oppression" " but a highly distinctive exercise of power.

Our argument in this book-that human life is being colonized by data and needs to be decolonized-is no approximation. We are not playing Indian. There is nothing metaphorical about the new era of coloniality that we will describe. By tracing continuities from colonialism's historical appropriation of vast territories, such as contemporary Brazil, all the way to data's role in contemporary life, we suggest that although the modes, intensities, scales, and contexts of today's dispossession are distinctive, the underlying function remains the same as under historical colonialism: to acquire large-scale resources from which economic value can be extracted.

If historical colonialism annexed territories, their resources, and the bodies that worked on them, data colonialism's power grab is both simpler and deeper: the capture and control of human life itself through appropriating the data that can be extracted from it for profit. If that is right, then just as historical colonialism created the fuel for industrial capitalism's eventual rise, so too is data colonialism paving the way for a capitalism based on the exploitation of data. Human life is quite literally being annexed to capital.

\section{Some Signposts}

This book's argument will therefore be a double one. Our first assertion is that our everyday relations with data are becoming colonial in nature; that is, they cannot be understood except as an appropriation on a form and scale that bears comparison with the appropriations of historical colonial- 
ism. Our second argument is that this new colonialism does not just happen by itself but is driven by the imperatives of capitalism. Whereas the relations between historical colonialism and what emerged as industrial capitalism became clear only after centuries, the new data colonialism occurs against the background of centuries of capitalism, and it promises to take familiar aspects of the capitalist social and economic order to a new and more integrated stage, a stage as yet too new to reliably name.

Three further aspects of our argument about data colonialism and its relation to capitalism's evolution must be noted at the start. One is that none of this would be possible without radical changes over the past thirty years in communication infrastructures, specifically the embedding of computer systems in human life at many levels. This book's analysis of data colonialism and capitalism's evolution takes very seriously the transformative role of information technologies and the resulting new infrastructures of connection. The second point is that such technological transformation does not change human life by merely existing. Technologies work, and have consequences for human life, only by being woven into what people do, where they find meaning, and how their lives are interdependent. Data colonialism requires the creation of a new social and economic order that is potentially as enduring as the order that enabled capitalist market societies from the nineteenth century onward. The third point concerns how the power relations generated by this emerging order work: data colonialism appropriates not only physical resources but also our very resources for knowing the world. This means that economic power (the power to make value) and cognitive power (the power over knowledge) converge as never before. Therefore, what is happening with data can be fully understood only against the background not just of capitalism but of the longer interrelations between capitalism and colonialism. The exploitation of human life for profit through data is the climax of five centuries' worth of attempts to know, exploit, and rule the world from particular centers of power. We are entering the age not so much of a new capitalism as of a new interlocking of capitalism's and colonialism's twinned histories, and the interlocking force is data. ${ }^{8}$

What do we mean by data? If a shopping list is scribbled on a piece of paper, we don't mean that. But if the list is entered on a mobile phone, per- 
haps on Google's Keep app, then we do mean that. Furthermore, if we consider the algorithms that collect information across all users of Keep to see what people are making lists of, we definitely mean that. For our very specific purposes, the concept of data cannot be separated from two essential elements: the external infrastructure in which it is stored and the profit generation for which it is destined. In short, by data we mean information flows that pass from human life in all its forms to infrastructures for collection and processing. This is the starting point for generating profit from data. In this sense, data abstracts life by converting it into information that can be stored and processed by computers and appropriates life by converting it into value for a third party.

This book introduces quite a few other concepts and neologisms, which are explained in detail as the chapters unfold. It might be useful, however, to provide some basic definitions and explain their relationships right at the beginning. Data colonialism is, in essence, an emerging order for the appropriation of human life so that data can be continuously extracted from it for profit. This extraction is operationalized via data relations, ways of interacting with each other and with the world facilitated by digital tools. Through data relations, human life is not only annexed to capitalism but also becomes subject to continuous monitoring and surveillance. The result is to undermine the autonomy of human life in a fundamental way that threatens the very basis of freedom, which is exactly the value that advocates of capitalism extol. These fundamental transformations of human life have dramatic consequences for the social world too. They enable what we call social caching, a new form of knowledge about the social world based on the capture of personal data and its storage for later profitable use. As social relations are thus transformed, we see the emergence of the Cloud Empire, a totalizing vision and organization of business in which the dispossession of data colonialism has been naturalized and extended across all social domains. The Cloud Empire is being implemented and extended by many players but primarily by the social quantification sector, the industry sector devoted to the development of the infrastructure required for the extraction of profit from human life through data.

For now, the good news is that these transformations are in their early stages. That is why an awareness of the historical roots of today's trans- 
formations is so vital. We must respect the uniqueness of the struggles of historically colonized peoples, but that doesn't mean we can't learn from them. Today's attempt to extract economic value from human lives through data has a systematic integration and depth that we argue is, in some respects, without historical precedent. But we see its features most clearly through their continuity with past relations between colonialism and capitalism. We fail to learn from that history at our peril.

\section{Introducing the Social Quantification Sector}

Some of the main actors in these transformations are already familiar. As just mentioned, we call them the social quantification sector. This sector has been growing for a long time, in part through marketers' accumulation of consumer data, such as credit card data, which began in the 198 os. $^{9}$ In the past fifteen years, however, the social quantification sector has achieved a new depth and complexity.

This sector currently includes the manufacturers of the digital devices through which people connect. By this we mean not just well-known media brands such as Apple, Microsoft, and Samsung but also the less-wellknown manufacturers of "smart" (that is, internet-connected) fridges, heating systems, and cars through which we never imagined we would communicate. Still less did we imagine that, in the quickly expanding Internet of Things, such devices would communicate with other devices about us. The sector also includes the builders of the computer-based environments, platforms, and tools that enable us to connect with and use the online world, including household names such as Alibaba, Baidu, Facebook, Google, and WeChat. There is also the growing field of data brokers and data processing organizations such as Acxiom, Equifax, Palantir, and TalkingData (in China) that collect, aggregate, analyze, repackage, and sell data of all sorts while also supporting other organizations in their uses of data. And, finally, the social quantification sector includes the vast domain of organizations that increasingly depend for their basic functions on processing data from social life, whether to customize their services (like Netflix and Spotify) or to link sellers and buyers (like Airbnb, Uber, and Didi). 
Beyond the social quantification sector is the rest of business, which has also been transformed in the "great data transition."10 Much of what ordinary businesses now do is crunch data from their internal processes and from the world around them; most businesses also depend increasingly on the work of the social quantification sector to target their ads and marketing. And beyond that is the vast array of everyday contexts in which people are integrating the outputs of that sector into daily life. The Cloud Empire is the larger outcome of this combined growth of the social quantification sector and data practices right across business and social life.

A few words of clarification about the term social quantification sector are needed. When we say social quantification sector, we use the word social to refer to that constantly changing space of relations and interconnections on which the quality of human life depends but whose meaning is endlessly contested in political and civic struggle. ${ }^{11}$ When we use the word social, we do not necessarily mean a well-ordered or well-integrated way of living together. For at issue in this whole transformation is precisely the quality of life that human beings will have together in the new capitalist social order. The capture of personal data through social caching and its storage for later profitable use-normal today but two decades ago barely imaginable-has major implications for our quality of life as human beings.

Social caching is often hidden from users of platforms and internet services under a veneer of convenience ("To use this app, you must first..."). Stripped of that veneer, the deal looks rather different. A key consequence of connecting with others in the era of data colonialism is submission to the continuous tracking of human life, a process known until recently as surveillance. As a leading computer-security expert, Bruce Schneier, put it, "The primary business model of the internet is based on mass surveillance." ${ }^{12}$ The all-seeing authoritarian state was a standard topic of twentieth-century literary dystopias (from Kafka to Orwell), ${ }^{13}$ but Schneier points to an even bigger problem: the building into corporations' routine operations of processes that conflict, as surveillance always has, with basic freedoms such as autonomy. The tracking of human subjects that is core to data colonialism is incompatible with the minimal integrity of the self that underlies autonomy and freedom in all their forms. 
This was the deeper meaning of Edward Snowden's revelations of US and UK security services' data-gathering in 2013. Suddenly, citizens became aware that today's pervasive state surveillance would be impossible without the continuous social-caching operations of commercial corporations. ${ }^{14}$ Since then, fears of a new "corporate governance of everyday life" have been growing. ${ }^{15}$ But other fears have started to overtake them, including the "fake news" scandals that have gripped politics since late 2016 in the United States, United Kingdom, and elsewhere. There are also fears that, because of polarizing forces online, "social media is ripping society apart"; ${ }^{16}$ fears from other commentators of a social dystopia driven by platforms' search for advertising income; ${ }^{17}$ and, finally, the fear that the targeting of news via social media platforms represents "the most lethal political weapon ever invented." ${ }^{18}$ Calls for the regulation of social media platforms and other information technology giants are becoming familiar. ${ }^{19}$ But none of these highly charged debates answers the underlying question on which this book will focus: should human beings in the twentyfirst century accept a world in which their lives are unceasingly appropriated through data for capitalism?

\section{Colonial Echoes}

This is where the long history of colonialism's entanglement with capitalism helps us move beyond the sound and fury of contemporary scandals and grasp the longer pattern of resource appropriation that gives shape to today's developments. Long before Karl Marx identified it as a force in the world, capital was already expanding in the sixteenth century, in the period most commonly identified with historical colonialism and the emergence of the Spanish, Portuguese, and British empires. Capital was acquiring new territories from which to extract resources and new bodies from which to extract labor. Those close relations between colonialism and capitalism (indeed, between colonialism and modernity in general) ${ }^{20}$ are important to our story; they help us grasp what is distinctive about the current expansionary phase of capitalism.

What do we mean by expansionary? Capitalism has been expanding from the start, in the sense of exploiting new resources, finding new ways 
of making profit, and finding new markets. But until recently, this expansion has been based on the exploitation of human production through labor relations, as classically theorized by Marx, resulting in the ever-greater transformation of physical nature as an input to capitalism. But the appropriation of human life in the form of data (the basic move that we call data colonialism) generates a new possibility: without ending its exploitation of labor and its transformation of physical nature, capitalism extends its capacity to exploit life by assimilating new or reconfigured human activities (whether regarded as labor or not) ${ }^{21}$ as its direct inputs. The result, we argue in chapter 1 , is the expansion of the practical scope of capitalist exploitation, but in ways that can be linked back to Marx's own sense of capitalism's expansionary potential. In this emerging form of capitalism, human beings become not just actors in the production process but raw material that can be transformed into value for that production process. Human life, in the form of profitably abstracted data, becomes more like the seed or manure that Marx noted became factors of capitalist production, having once just been part of human beings' cycle of interaction with the land. ${ }^{22}$ This transformation of human life into raw material resonates strongly with the history of exploitation that preceded industrial capitalism-that is, colonialism.

The very concept of raw material has deep colonial roots. Raw, in this context, means available for exploitation without resistance rather than a substance that needs no processing. The natural environment itself first had to be reconstructed so that it became available for value extraction. ${ }^{23}$ Then, through the practice of slavery (which preceded colonialism but which reached a massive scale under colonialism), human bodies were transformed into a raw material for capitalism in the form of slaves. Historians have warned us against treating slavery-usually imagined as a premodern practice-in isolation from the development of industrial capitalism. The plantation and the factory coexisted for a long time. ${ }^{24}$ The treatment of human beings as mere property stimulated the rationalities of profit maximization, accounting precision, and data optimization that we now tend to associate with modern rationality. ${ }^{25}$ Here is an eloquent description by the historian of the capitalist slave plantation, Edward Baptist: 
So push a button (with the index finger of your right hand) on the machine of the trading world, and things happen to benefit the man with sterling bills, a huge pile of cotton, a long roster of slaves, abundant credit that allows him to extend his reach across time and space. ${ }^{26}$

What if comparable processes for abstracting human life are today enabling new, extended forms of economic extraction? Human data is not actually raw, ${ }^{27}$ but business often imagines it is. Human life first needs to be configured so as to "naturally" generate a resource such as data. Momentary data about one individual's actions or properties is worthless unless it can be combined with data about other individuals, actions, moments, and properties to generate relations between data points, ${ }^{28}$ and that is why an infrastructure has been built to ensure this. The world of internet-based connection is a world in which new types of corporate power, with privileged access to data streams extracted from the flow of life, can activate a metaphorical button-an apparatus of extraction, whether platform, app, or AI system-that reconfigures human life so that it contributes continuously to the collection of data and thereby, potentially, to the generation of profit.

The result of such data relations is certainly not a new slavery, since nothing can compare to the terrible violence of that institution (the practice of "distinguish[ing] every bad thing by the name of slavery" was already criticized by Frederick Douglass in the mid-nineteenth century). ${ }^{29}$ But that should not blind us to what remains a disturbing line of continuity: as happened historically, but under new conditions, human life today is becoming the object of appropriation for extraction and, in the process, enabling capitalism to move to a still higher scale and integration of operation. Our intent is not to make comparisons to the detailed contents or form of historical colonialism but to focus on colonialism's enduring function, which we see as enacting illegitimate appropriation and exploitation and as redefining human relations so that the resulting dispossession comes to seem natural. It is such continuities that the term data colonialism enables us to grasp. 


\section{What Is Data Colonialism?}

More explicitly defined, data colonialism is our term for the extension of a global process of extraction that started under colonialism and continued through industrial capitalism, culminating in today's new form: instead of natural resources and labor, what is now being appropriated is human life through its conversion into data. The result degrades life, first by exposing it continuously to monitoring and surveillance (through which data is extracted) and second by thus making human life a direct input to capitalist production. Data colonialism is, in other words, an emerging order for appropriating and extracting social resources for profit through data, practiced via data relations. Unlike historical colonialism, whose vast profits helped create the preconditions for what we now know as industrial capitalism, data colonialism emerges against the backdrop of the entire intertwined history of colonialism and capitalism. This means that the basic colonial move of appropriating data from human life (data colonialism) works hand in hand with social arrangements and technological infrastructures, some that emerged during earlier capitalism and some new, that enable that data to be transformed into a commodity, indeed, a direct input to contemporary capitalist production.

Although the site of data colonialism that we most often notice is the social quantification sector, and particularly the personal data extraction practiced by social media platforms, the basic extractive principles underlying data colonialism have been gestating in the business methods of modern capitalism for three decades. The original context was industrial capitalism's progressive globalization in the late twentieth century through trade liberalization and extended supply chains as well as its financialization through an explosive growth of debt (both corporate and personal) and the acceleration of global capital flows. In this general context, the information infrastructures emerged that enabled people and processes to be connected to each other under conditions that facilitate data extraction. ${ }^{30}$

Take an example far from social media: the discipline of logistics. The goal of logistics is to use continuously connected data flows to organize 
all aspects of production across space and time within global commodity chains. ${ }^{31}$ It was enabled, decades before social media, by software inventions such as the relational databases that help businesses find patterns in huge data flows across diverse sources and locations. ${ }^{32}$ If logistics aims to rationalize production, the recent growth of the Internet of Things (IoT) aims to incorporate consumption-what we do with products after we buy them-into an extended chain of profit extraction through the processing of data. ${ }^{33}$ The bigger vision of the IoT, and of data colonialism as a whole, has been expressed by a company normally seen as the enemy of the entrepreneurs who built social media platforms-IBM. By turning the human environment into a network of listening devices that capture data about all activities, IBM suggests that they can "liquify" areas previously inaccessible to capital. The company put it this way: "Just as large financial marketplaces create liquidity in securities, currencies and cash, the IoT can liquify whole industries, squeezing greater productivity and profitability out of them than anyone ever imagined possible." ${ }^{34}$ In this view, every layer of human life, whether on social media platforms or not, must become a resource from which economic value can be extracted and profit generated. The processing power of artificial intelligence is a key tool in all these developments.

Far from being a feature of the West only, the growth of the social quantification sector, logistics, and the IoT in the context of rapidly expanding uses of artificial intelligence is a core development and policy goal in China too. ${ }^{35}$ The social quantification sector emerges as an arena of commercial and geopolitical competition between the West (particularly the United States) and China.

We can capture the core of our double argument most succinctly by characterizing data colonialism as an unprecedented mutual implication of human life and digital technology for capitalism. None of this would have been possible without the emergence in the past three decades of a radically new technological infrastructure for connecting humans, things, and systems, known generally as the internet. We have written this book because it is time to count the costs as well as the much-proclaimed benefits of such connection for human life. 


\section{The Book's Structure at a Glance}

In telling the story of this double transformation (a new colonialism and an extended capitalism), our goal is to equip readers to better see the world that is being built for them and to imagine a different one.

Chapter 1 lays out our argument's foundations: the concepts of data colonialism and capitalist data relations, their contextualization within the twinned histories of capitalism and colonialism, and capitalism's recent turn toward the capitalization of human life itself. We will explain how much recent critique of data trends misses two crucial ingredients: the radically reconfigured social world that computer-based connection makes possible and the unprecedented fact that the emerging colonial/capitalist power structure has at least two poles of power in what, until now, we have called the West and in China (with India an important player over the longer term).

Chapter 2 then explains in more detail the workings of the social quantification sector as an economic and organizational transformation within the emerging larger formation of the Cloud Empire. We will map out the relations between the multiple ways in which data is transforming the capitalist economy on the basis of data colonialism's fundamental mode of appropriation. An interlude is offered following chapter 2 for readers who might need a quick overview of colonialism and the critical and theoretical responses to it. Chapter 3 places our overall analysis in the context of the much longer history of colonial appropriation, demonstrating the hidden patterns that get missed until we look at the contemporary era through a colonial lens. As a result, we see the recent rise of data as a mode of social and economic ordering within the much longer perspective that decolonial theorists have called coloniality: the long-term skewing of the world's economic-resource distribution in favor of particular types of power formations and the justification of this skewing by an equally biased distribution of knowledge resources, loaded until very recently in favor of the "West."

The next two chapters build on the framework established in the first three chapters to examine more closely the social order emerging from 
data colonialism and what it means for human beings and their quality of life everywhere. Chapter 4 asks what is happening to the social domain in datafied societies and, in particular, what is happening to our knowledge of the social world as it becomes transformed by data relations. Datadriven changes to social knowledge also have major implications for injustice and inequality in the social world. Chapter 5 turns to the implications of data colonialism for the very nature of human subjecthood and specifically for human autonomy. Autonomy may be a compromised concept in some forms, but it is one we cannot do without, because it provides the normative basis for resisting the violence of data relations. Without the notion of autonomy, and in particular the minimal integrity of the self that underlies it, democracy and freedom in any form would make little sense.

Chapter 6 brings the book's threads together, assessing where data colonialism and the capitalization of life are likely to head in the foreseeable future and what type of larger social order/disorder this will entail. From there, a postscript suggests ways to imagine forms of human connection that may be free of the costs of data colonialism's regime and to begin orienting ourselves toward possible strategies for resisting data colonialism on the ground.

This book is an attempt to disentangle a historical moment of great complexity. As the first subjects of an emerging data colonialism, we can make sense of this complexity only within the much longer history of colonialism and capitalism. We also need to do a considerable amount of interpretative and analytical work across today's societies and economies. In writing this book, we have been fortunate enough to build on much excellent work within the past decade that has begun to uncover the shape and dynamics of human life's appropriation through data. ${ }^{36}$ But in searching for a larger theoretical framework to make sense of the whole sweep of these developments - the framework of data colonialism - we have had to forge some new connections and take an eclectic path in terms of theory. Rather than positioning our argument exclusively within Marxism, postcolonialism, Foucauldian analyses of biopolitics, or critical-information science, our aim is to put these perspectives into conversation, taking the best from each to forge a new starting point adequate to today's complex transformations and their hidden violence. 
We hope that, like us, you will find worthwhile the effort to trace the "inner connection" 37 of what is happening with data. It is now urgent to better understand the hidden and not-so-hidden costs of something human beings have until now generally seen as good: connection. Only from better understanding can come the chance of resisting today's terms of connection and the forging of better ones. 
This page intentionally left blank 
THE COSTS OF CONNECTION 
This page intentionally left blank 